\title{
Empathy without Simulation
}

Matthew Ratcliffe

Empathy has been conceived of in various different ways. It is generally assumed to involve some kind of experience of someone else's experience, and I will take that much for granted. However, there is disagreement over what the relevant achievement consists of and how it is accomplished. ${ }^{1}$ The orthodox view in current philosophy of mind is that empathy centrally involves mental simulation: one comes to understand another person's experience by replicating it in the first-person. In this chapter, I adopt a different approach. I examine how empathy is described in the context of clinical practice, and then use this as a basis from which to develop and defend an account that has wider applicability. Empathy, of the kind I am concerned with here, is not a matter of simulation. Instead, it consists in a kind of openness to interpersonal difference, which can be integrated into an exploratory process.

The initial openness is itself sufficient to qualify as empathy, but more sophisticated empathic achievements involve varying degrees of exploration. ${ }^{2}$ Simulation can and often does contribute to an empathic process of this kind, but as an optional ingredient that is neither necessary nor sufficient for empathy. Insofar as the account that I arrive at emphasizes a distinctive kind of second-person attitude, it complements an approach originating in the phenomenological tradition of philosophy (e.g., Stein [1917] 1989; Zahavi 2014). However, I also recommend revision, clarification, and elaboration of that approach: it places too much emphasis on a perceptual or quasi-perceptual experience of someone else's mental life, operates with a conception of second-person experience that is too accommodating, and does not adequately acknowledge the way in which empathy involves a structured process.

Commented [A1]: This sounds so hopeless from the get-go that I'm wondering what the attraction is in the first place. Not really your job in the paper, but it does have me wondering. (Why hopeless? Consider empathy for someone who is grieving. Does my empathizing involve or, worse, require "replicating" her grieving experience? How would I do that when it is her loss and not mine?

Commented [A2R1]: I wholly agree. But, for some reason, lots of philosophers not only take this conception seriously but take it as given. I haven't added anything here, but the topic of why people are attracted by such views is perhaps something to address on another occasion. 
Whenever it is claimed that empathy is $x$ and not $y$, there is the risk of descending into a merely verbal dispute. If — as is widely acknowledged — uses of the term 'empathy' do not have a common referent, seemingly substantive disagreements over what it consists of could turn out to involve different and equally legitimate uses of the term. ${ }^{3} \mathrm{I}$ am keen to avoid this potential quagmire. The position I defend in what follows is that 'empathy' often does refer to something distinct from simulation. Hence, if we want to understand the kinds of cognitive achievement that people do refer to as empathy, we need to accommodate this. Of course, the simulationist could concede this while continuing to insist that there is at least one other kind of empathy. And I doubt that there is a principled way of arbitrating between accounts that allow for different kinds of empathy and accounts that take only one of them be worthy of the name. Nevertheless, the process described here is at least a better candidate for the title 'empathy' than any kind of simulation. In the cases I consider, openness to difference without simulation is sufficient for empathy whereas simulation without openness is not. In addition, it is likely that simulationist accounts often refer to the same kind of empathic achievement that I describe, but misconstrue it. Hence, if we want to be pluralists about empathy, a kind of empathy that is importantly different from simulation needs to be acknowledged. And, if we seek a unitary conception, there are good grounds for choosing it over simulation.

\section{Empathy as simulation}

Simulationist theories of empathy maintain that empathizing with person A's experience centrally involves having a first-person experience similar to that of A. An influential recent account is offered by Alvin Goldman, who refers to the "simulation (or empathy) theory," thus identifying the two (Goldman 2006, 17). Stueber $(2006,4)$ similarly assumes a relationship of identity. Simulationists generally acknowledge that B's replication of A's 
experience is not sufficient for B's empathy with A. B's mental state must also be caused by A's. This does not suffice to distinguish empathy from phenomena such as emotional contagion, where B's mental state is similar to A's, as well as caused by it, but without B directing any attention towards A or having any understanding of A's mental state. Hence it is added that B must attribute the mental state to A. De Vignemont and Jacob (2012) further propose that B must care about A, which rules out counter-intuitive examples such as B's experiencing something of A's grief and then laughing at it. Recent discussions tend to identify two broad types of simulation: (i) implicit simulation, which is a ubiquitous, nonconscious replication process, facilitating a perceptual or perception-like appreciation of others' experience, and (ii) explicit simulation, which involves effortful, conscious modelling and is employed less often. Hence the same distinction is applied to empathy. For instance, Goldman (2011) discusses non-conscious "mirroring" processes as well as "reconstructive empathy," while Stueber (2006) allows for a quasi-perceptual "basic" empathy, as well as "reenactive" empathy. ${ }^{4}$

Explicit simulation consists in a distinctive kind of imaginative achievement, whereby one "replicates," "recreates," "reconstructs," or "re-enacts" the experience of another person. It is to be distinguished from all those cases of imagination that involve imagining that $p$, rather than actually experiencing $p$. In other words, it is a form of "enactment imagination" (Goldman 2006). More specifically, it is a matter of re-enactment and is thus to be distinguished from forms of enactment imagination that do not involve experiencing something as another person did or does. These include imagining one's own experiences in various situations, such as winning the lottery, starting a new career, meeting a particular person, and succeeding or failing to do something. Other cases involve imagining some entity or state of affairs without explicitly attributing the experiential content to oneself in contrast to others, or to someone else in contrast to oneself. For instance, one might imagine what a 
new building will look like from immediately beneath it, what a city is likely to look like after a major earthquake, how a species of dinosaur might have sounded, and so forth. Simply imagining $p$ in this way is distinct from imagining how I or another person would experience

$p$.

It is important to further distinguish two kinds of perspective-taking that "explicit simulation" or "re-enactive empathy" might be said to involve. According to one, the empathizer modifies her first-person perspective by factoring in situational and perhaps also psychological differences, generates a first-person experience, and attributes it to the other person. However, some maintain that this does not suffice for empathy; it yields only a modified version of what it is like for me, whereas empathy requires an experience of what it is like for you. Empathy therefore involves somehow taking on the first-person perspective of another person and seeing the world through her eyes. For example, Gordon (1995a, 1995b) conceives of simulation and empathy in this way, as the taking up of another person's firstperson perspective. ${ }^{5}$ Hence three kinds of simulation are to be distinguished: (i) implicit simulation; (ii) explicit modification of one's own first-person perspective; (iii) explicit adoption of someone else's first-person perspective. The kind of empathy described in what follows is not captured by any combination of the three. My primary focus will be on the contrast with explicit simulation, although I will later address implicit simulation as well.

\section{Empathy in clinical practice}

In this section, I will extract a number of recurring themes from accounts of empathy offered by clinicians, and show how they point towards a singular, cohesive conception of empathy. The sections that follow will then clarify, elaborate and defend an account along these lines. I focus on clinical empathy for three reasons. First of all, it often involves attempting to 
understand experiences that are very different from one's own, pointing to a problem for simulation: we can sometimes empathize with experiences that we cannot simulate. Second, empathy is central to the work of many clinicians and therapists, and their descriptions of it may contain insights that are missed by so-called "armchair" theorists. Third, the accounts of clinical empathy considered here are not pre-occupied with debates over the cognitive role(s) of mental simulation. So we can ask whether and to what extent their content is consistent with simulation theories of empathy, something we could not do if they were already framed in simulationist terms.

Empathy is often characterized as a matter of entering into or occupying someone else's perspective. Talk of perspective-taking could be construed in terms of duplicating someone else's perspective, an interpretation that may be largely responsible for the appeal of explicit simulation. But it can also be construed more literally, as analogous to entering a place or occupying a room, exploring it over a period of time, and gaining a better understanding as one proceeds. Consider the following description, offered by the therapist Carl Rogers:

To sense the client's private world as if it were your own, but without ever losing the "as if" quality — this is empathy, and this seems essential to therapy. To sense the client's anger, fear, or confusion as if it were your own, yet without your own anger, fear, or confusion getting bound up in it, is the condition we are endeavouring to describe. When the client's world is this clear to the therapist, and he moves about in it freely, then he can both communicate his understanding of what is clearly known to the client and can also voice meanings in the client's experience of which the client is scarcely aware. (Rogers 1957, 99) 
A number of interrelated themes can be identified in the passage. It begins, as is often the case, with something not unlike simulation-you experience someone else's world as if it were your own. However, matters are not so clear. Rogers states that the other person's anger is experienced, but in a way that differs from being angry oneself. It is also worth noting that he "endeavours" to describe the experience of empathizing, suggesting that it is not easy to convey and that he should be interpreted with caution. Furthermore, his description indicates that there is more to empathy than this. One "moves about" in the client's world, in a way that the client herself does not, suggesting an exploratory process through which the other person's experience is progressively revealed to the therapist. There is also a degree of communication and cooperation: empathic understanding of A by B is related by B to A. Communication of empathy to the target person is of course compatible with simulation. However, if empathy is construed as a temporally extended process (as it usually is in clinical contexts) rather than an episodic achievement, then the two are inextricable: a client's appreciation of the therapist's attitude towards her regulates interaction with the therapist in ways that feed into the continuing empathic process, to the "moving about." Empathy, when it operates most effectively, is dialogical and - to varying degrees - cooperative.

A further point to note is that the therapist has an understanding of the client's experience that differs from the client's own understanding and can involve greater insight. As Margulies $(1989,128)$ puts it, a therapist can engage with aspects of experience that the client herself is "not fully aware of." These insights can then be drawn upon by the client to reinterpret and regulate her own experience. Hence an empathic process has a moving target; it shapes and reshapes rather than just reveals experience. Of course, it could be maintained that an experience is replicated and afterwards interpreted by the therapist. But a two-step routine of that kind cannot be applied convincingly to lengthy interactions, which involve testing, revising and elaborating understandings of a client's experience. The therapist does 
not have a first-person experience that is isomorphic with the client's, because she has a different kind of insight into it from the outset. ${ }^{6}$

Other accounts of empathy in clinical and therapeutic settings identify similar themes. For instance, the psychiatrist Leston Havens construes empathy as a collaborative endeavour, one that can be hampered in various ways by implicit and explicit strategies of noncooperation. He distinguishes several kinds of empathy: motor; passive (where a therapist waits to be affected by a client); cognitive; affective; and perceptual. So we might regard this as a pluralist conception. However, all have a potential role to play in a unitary process, in a self-transformative "exploration" of the other person's perspective: "to find another, you must enter that person's world. The empathic visitor then discovers what he has taken for granted in his own world" (Havens 1986, 21). Margulies $(1989,97)$ likewise construes empathy in a dynamic way—both parties shape and adjust to each other's perspectives; empathy involves "individual world views confronting, assimilating, and accommodating to one another." And, despite occasional talk of "entering" another person's perspective, most accounts state that the therapist maintains her own perspective throughout, experiencing and interpreting the client's emotions and feelings in a way that differs from that of the client:

"The clinician 'enters into' the perspective and experience of the other person by using verbal and nonverbal cues, but she neither loses her own perspective nor collapses clinical distance" (Coulehan et al. 2001). ${ }^{7}$ Hence "entering into" or "occupying" a perspective is to be distinguished from simply "adopting” it.

Another central theme is that of appreciating difference. Empathy requires an initial acknowledgement of actual or potential differences between one's own "world" and that of the patient, a distinctive kind of "openness" towards the other person. For instance, Larson and Yao $(2005,1100)$ remark that, "to cultivate an acute ability to empathize with others, one needs patience, curiosity, and willingness to subject one's own mind to the patient's world." 
Again, this "subjection" is not simulation; one does not replicate experience in the firstperson; one encounters it as someone else's, and explores it by attending to that person. As Halpern (2003, 670-671) observes, the empathic clinician's attention is directed principally at the patient and not "unduly diverted to introspection." For Halpern, empathy is a style of conduct, which involves proceeding with openness and curiosity; it is "not an additional task but rather an adverb" (2001, xi). Being empathic involves a way of first approaching and then interacting with the other person; it is not a matter of performing a specific kind of episodic cognitive feat (see also Margulies 1989).

Of course, imagination is also important, but its principal role does not seem to be that of replicating someone else's experience. More importantly, imagination contributes to a progressive appreciation of experience, whereby one comes to understand it as a cohesive whole: "imagination work must be done to unify the details and nuances of the patient's life into an integrated affective experience" (Halpern 2001, 88). The task of empathy is not simply to understand an experience in isolation, but to make connections. Even if one did replicate an isolated experience (whatever that might be; I am unsure how to individuate 'experiences' and I use the plural term in a noncommittal way) and attribute it to the other person, this would not amount to empathic understanding. Empathy involves situating experiences in the context of a person's life, against the backdrop of her hopes, aspirations, projects, commitments, concerns, loves, fears, disappointments, and vulnerabilities. As we will see, no singular imaginative achievement is sufficient for this.

It has been suggested that clinical empathy is a form of "professional interaction" (e.g., Mercer and Reynolds 2002, 10). Hence it might be objected that what we have here is a skill acquired through exposure and training, rather than a wider-ranging ability of the kind that simulation addresses. There is also the methodological worry that all of these accounts are first-person interpretations of practice, which may be shaped by common exposure to and 
acceptance of certain unstated theories. It is right to raise such concerns, but I do not think they apply. Empathy in this and other contexts does indeed draw on skills that people acquire to varying degrees. And I will suggest that the following themes together point towards a conception of empathy that differs from simulation and is not specific to clinical practice:

1. Appreciation of difference is more central to empathy than the achievement of similarity.

2. Empathy is a matter of engaging in, or being open to the possibility of engaging in, an exploratory process.

3. Empathy involves a distinctive kind of attitude towards the other person.

4. Sophisticated empathic understandings are usually collaborative endeavours.

5. We do not empathize with isolated experiences, but situate them within a wider context.

6. Empathic appreciation of someone's experience can be shaped by an understanding of it that differs substantially from a first-person understanding.

I will now further develop and defend an account of empathy along these lines. Central to it is (1); I will first argue that recognition of difference can be sufficient for empathy, and that simulation is therefore inessential. Then I will turn to (2), showing how this recognition facilitates and is incorporated into an exploratory process. Following this, I will address (3), and further clarify what an empathic attitude consists of. I will not consider (4), (5), and (6) in as much detail, given that they are not so central to my account, but what I will say is consistent with them. Drawing all of this together, I will argue that explicit simulation is sometimes a misconstrual of what I describe and sometimes a poor substitute for it, while an appeal to implicit simulation proves uninformative. 


\section{Openness to difference}

The starting point for empathy (or, at least, the kind of empathy I am concerned with here) is openness to potential phenomenological differences between self and other. A greater appreciation of what those differences actually are may then be acquired through exploration. Although exploration usually facilitates at least some positive understanding of the other person's experience, the realisation that "A is unlike me in respects $p$ and $q$ " can itself count as an empathic achievement. The gap does not need to be bridged, by simulation or by anything else, for empathy to arise. One might think that appreciation of difference goes without saying and hardly suffices for empathy — the task is to bridge differences with similarities and thereby facilitate greater understanding. However, it is important to appreciate the extent to which phenomenological similarity is presupposed when we interpret each other in mundane circumstances. When I happen upon a friend while walking through town, I take for granted that we inhabit a common framework of norms such as 'one does not walk in the middle of the road' and 'one pays for things that one takes out of shops.' I similarly assume that various artefact functions are appreciated, without conscious inference, in much the same way by both of us: we live in a shared world of buses, litter bins, cafes, and so on.

It might be objected that norms and such are not part of our phenomenology and therefore not potential targets for empathy, assuming that the object of empathy is someone else's experience. However, so long as we understand 'experience' in a permissive way, as accommodating all instances of $p$ where there is phenomenological access to $p$ without inference, then many norms and functions do fit the bill. And that is how I think of 'experience' here. I see that the other driver is on the wrong side of the road; I encounter a 
chair as something for sitting on. Appreciating that others do too is not a matter of first experiencing $m y$ world from $m y$ perspective and subsequently projecting it wholesale onto them. Instead, interpersonal differences are understood against the backdrop of a social situation that is taken from the outset as ours. I might recognise that you are desperate to catch the bus while I am not but, in so doing, I continue to assume that we share much in common. Usually, it does not occur to me to suspend the assumption that you are familiar with what buses are and with all the associated norms.

Suspension of ordinarily presupposed commonality is central to empathy. Once B has suspended the unquestioned assumption that A shares $x$ with $\mathrm{B}, \mathrm{B}$ can explore whether and to what extent A does share $x$. Suspension comes in varying degrees and encompasses many different aspects of experience: social and cultural norms; the emotional import of various states of affairs; the cognitive and practical abilities one brings to bear on a situation. An unusually heightened openness to difference might involve B's ceasing to assume that A experiences space and time in the way B does, wondering whether A could experience other people in a way that is radically different, or contemplating a range of other ways in which the structure of A's experience might differ profoundly from B's (Ratcliffe 2012, 2015). Exactly what is suspended will vary from case to case, and having a sense of which presuppositions to suspend in which circumstances is a skill, something that some are better at than others.

One might think that all of this is compatible with simulation. In simulating another person, we put aspects of our own first-person perspective out of play in order to model her first-person experience. However, there are good reasons for rejecting that view. First of all, recognition of difference can itself suffice for empathy, as exemplified by accounts of what it is to feel empathized with. In the presence of an empathic listener who is open to difference, the other party may, as Havens $(1986,24)$ puts it, "light up in recognition of your sudden 
presence in their lives"; they "feel found, and not in the sense of found out or criticized." Pienkos and Sass $(2012,32)$ similarly observe that an interviewer's acknowledgement of profound difference, conveyed by the asking of certain kinds of question, can itself nurture a sense of being empathized with: "patients can feel quite moved in being asked about these experiences." Indeed, this is a recurrent theme in accounts of clinical empathy. As Margulies $(1989,12)$ remarks, empathy requires "the capacity to go against the grain of needing to know." One does not simulate or project, so much as restrain oneself from the habitual tendency to assume commonality. The point is not specific to clinical practice though. For example, in her work with prisoners, Medlicott $(1999,214)$ construes empathy as the achievement of a sustained interpersonal connection, one that involves respecting prisoners as "knowledgeable sources," as well as being "non-judgemental." Similarly, in the context of fieldwork in cultural anthropology, Throop $(2010,771)$ argues that empathy is a dynamic process, one that does not require "some set of homologous experiences." Rather, there are “moments of connection" and "feelings of mutual understanding." Where phenomenological isomorphism is not involved at all, simulation is redundant. Granted, appreciating phenomenological difference implies at least some grasp of what the other person does experience, but this can remain vague, ambiguous and indeterminate, without amounting to a failure of empathy. Openness to difference does not consist of a concrete act of imagination, whereby one generates an experience with a specific content and contrasts it with one's own experience. Rather, it is a more enveloping attitude that is adopted towards the other person, which determines the scope of one's empathic imaginings and thus the kinds of experience that one is able to contemplate attributing to her.

Furthermore, the view that we can bridge substantial phenomenological differences by imaginatively recreating the experiences of others is highly implausible. Consider types of psychiatric illness that disrupt interpersonal abilities so as to limit the patient's ability to 
empathize with others (where empathy is construed in a non-committal way as "appreciating something of their experience”). For example, Jaspers ([1913] 1963, 64) describes anomalous forms of experience where "other people seem dead, patients feel they only see the outside and are no longer conscious of the psychic life of others." An experience that itself involved an absence of empathic ability could not be empathized with via replication, as replication of $p$ would interfere with any attempt to empathize with $p$. This applies even where an empathizer has had a past experience of $p$ himself. Re-living it would shut down empathy with the other person, and so it is unclear how generation of $p$ could aid understanding of someone else's experience of $p$. Yet it is also far from clear that we cannot empathize with any of those people whose own ability to recognize and appreciate the distinctiveness of others' perspectives is compromised. That would apply to a wide range of psychiatric conditions that are accepted to involve degrees and kinds of empathy failure, including narcissistic personality disorder (Ritter et al. 2011), psychopathy and autism (Blair 2005), and some forms of depression (Ratcliffe 2015). Now, the simulationist need not insist that one has to model all aspects of the other person's experience. Nevertheless, where one seeks to empathize with an experience that centrally involves a pervasive sense of interpersonal alienation, it is unclear how one could do so by simulating an experience that does not involve a pervasive sense of interpersonal alienation. And, if one could do that, it is unclear why simulation should be necessary at all, given that profound experiential differences are, by implication, bridged by something other than simulation. This problem does not arise for an account that emphasizes appreciation of difference rather than generation of similarity.

One might respond that such objections apply only to certain extreme cases and that more mundane occurrences of empathy do involve bridging difference by generating similarity. To be more specific, in all those cases where a positive understanding is achieved, we owe this to explicit simulation, to specifically re-enactive imagination. However, consider 
ubiquitous features of our psychology, such as habitual dispositions and moods. Goldie (2011) argues that many of these are psychologically impossible to simulate. Certain "character" or "personality" traits shape a person's experience in the ways they do partly because the person is not reflectively aware of their influence, as do many moods. If the empathizer explicitly recognizes their influence on the target person's experience, she cannot simulate the roles they play, as they can only play those roles where first-person insight is lacking. However, if she does not recognize them, she cannot feed them into a simulation at all. So she cannot, by means of explicit simulation, duplicate the other person's perspective. As Goldie notes, one might be able to simulate how one would act in a person's situation, “in his shoes.” But, insofar as one is unable to imaginatively take on board moods and habitual dispositions, one will be unable to transcend one's own perspective to appreciate how it is for him. Others raise complementary concerns. For instance, Slaby (2014) argues that experience has a foreground-background structure that resists any attempt at effortful replication, and Margulies $(1989,34)$ maintains that experiences cannot be understood in isolation from the "totality of the person." The common thread of these criticisms is that simulation presupposes an overly atomistic conception of experience and that, once the inextricability of seemingly localized experiential contents from a wider phenomenological context is acknowledged, there are no grounds for the view that explicit simulation is even psychologically possible, other than in fairly trivial cases where two parties are much alike from the outset. It might be objected that the failure of simulation here should not be taken to imply that we do not empathize by simulating in such cases, just that we are sometimes not very good at it. However, the point is that empathy is acknowledged to be possible in various situations where simulation is not, demonstrating that simulation is not required for empathy, in the relevant sense of the term. ${ }^{8}$ 
Even so, it could be argued that there are plenty of other instances where simulation plausibly has an important role to play in the kind of empathic attitude I have described. To make that case, the less demanding conception of simulation could be adopted: one uses one's own first-person perspective to model that of another, rather than trying to somehow occupy her first-person perspective. There are surely many occasions when our own past experiences enable us to appreciate similar experiences had by others. For instance, experiencing profound grief oneself might well render one better able to empathize with others' grief. But consider how empathy could still fail in such a case. Suppose an "empathizer," one of whose parents died some years ago, encounters someone who has just lost a parent and says "I know just how you feel; one of my parents died too." Now suppose that the grieving person feels she has not been understood, that her experience has not been acknowledged at all. Why might that be? Here are two scenarios: (i) the empathizer resorts to typifying, where her experience and that of the target are both categorized as instances of the type 'experience of losing a parent,' which is applied in a generic way that does not engage with a particular individual's experience of grief; (ii) the empathizer imposes his own experience on the target, in a way that again fails to acknowledge the distinctiveness of the latter's experience. First-person accounts of grief often emphasize the particularity of it, and its resistance to both kinds of understanding. As the novelist Julian Barnes remarks:

We are bad at dealing with death, that banal, unique thing; we can no longer make it part of a wider pattern. And as E. M. Forster put it, "One death may explain itself, but it throws no light upon another." So grief in turn becomes unimaginable: not just its length and depth, but its tone and texture, its deceptions and false dawns, its recidivism. ... Grief, like death, is banal and unique. (Barnes 2013, 71-72) 
Past experience can of course inform empathy by supplying some sense of what another person might be experiencing. No doubt, it is often the case that B empathizes with A's experience of $p$ but could not have done so had B not experienced something much like $p$ herself. However, the fact that recalling one's own experience of $p$ (and maybe reexperiencing something of $p$ in the process) can enhance one's ability to understand a $p$-like experience does not imply that it does so by operating as a simulation, unless it is insisted that past experiences can only inform responses to current situations by operating as simulations. Any use of episodic memory that involved somehow detecting similarities between remembered situation $p$ and present situation $q$ would thus qualify as a simulation. And that is surely too permissive to be informative.

Nevertheless, simulation is surely involved in some cases. Suppose you seek to understand how someone is feeling and ask yourself "how would I feel in that situation?", after which you either recall how you did feel or imagine how you might feel. Here, it is plausible to maintain that first-person experiences are generated in order to understand second-person experiences, and that they therefore qualify as "models" or "simulations." However, what remains essential to empathy is an attitude towards the other person's experience that involves receptiveness to potential difference. Successful empathy demands recognition of the gap between actual or imagined first-person experience and the content of second-person experience. Simulation can help to generate possibilities and likelihoods, which enhance one's sense of what the other person might be experiencing and thus inform engagement with her experience. But it does not serve as a substitute for exploration; empathy involves abstaining from projection, rather than projecting an adjusted simulation. In cases where there is projection of one's own actual or imagined experience upon the other person (with or without modification) and therefore no gap, there is a lack or failure or empathy, which may or may not be detected by others. Hence, while openness to difference 
without simulation suffices for empathy, simulation without openness to difference does not. Simulation is therefore neither necessary nor sufficient for empathy. ${ }^{9}$

\section{Empathic processes}

One might worry that I have so far construed empathy in an overly negative way. It can also involve a positive appreciation of what someone does experience. And how else could this arise than through a kind of imagining that serves to replicate, re-enact, or reconstruct that person's experience? Although I maintain that openness to actual and potential experiential difference can itself amount to an empathic achievement, I also acknowledge that many instances of empathy involve more. However, this should not be credited principally to explicit simulation. Rather, openness is often the starting point for an interpersonal process, through which some appreciation of what the other person does experience may be acquired. The process has a cohesive, diachronic structure, and an important aspect of it is the manner in which information is obtained from the other person. There is a sense of whether and how one should follow up on what has been grasped. Empathy often requires patience and listening. It can involve allowing the other person to relate an experience herself, rather than rushing in to tell her that one has understood what she's going through. Even if one manages to construct an accurate account of what she is experiencing, such hastiness can disrupt a longer-term process, giving the target person a sense of not being understood, of not being engaged with in the right way. ${ }^{10}$ Again, these themes are explicit in accounts of clinical empathy. Empathy, it is said, "allows the patient to feel understood, respected, and validated," giving rise to a kind of "feedback loop" that facilitates progressive clarification of experience (Coulehan et al. 2001, 222). It is not a singular, episodic achievement but a dynamic, interpersonal process of whatever duration. 
The expectation that we follow-up on what the other person says and does, and - in so doing - increasingly situate her experience in relation to her life, further shows how empathy involves experiential contextualization of a kind that cannot be achieved through simulation alone. Consider empathizing with someone's anger, for instance. This does not involve becoming angry, and it is not simply a matter of being able to experience her anger either. Instead, one finds out what has made the person angry, engaging with her cares, concerns, projects and life events in the process. Various different kinds of empathy that might be distinguished, such as "affective" and "cognitive" empathy (e.g., Havens 1986), are thus diachronically unified. They are aspects of a process, rather than distinct empathic achievements. ${ }^{11}$

As already noted, while it might seem plausible to suggest that we can simulate an isolated experience, it is much less plausible to maintain that we are able to simulate a more elaborate set of cares, concerns, and commitments, along with a tapestry of interconnected events and interpretations. But how, one might ask, do we come to appreciate this richer context? One suggestion, which I find plausible, is that we rely largely on narrative understanding. Goldie (2000) argues that empathy consists in a certain way of imagining the narrative and character of another person. Once the emphasis is placed on a cooperative process rather than exercises of first-person imagination in isolation from interaction, it becomes clearer how such narratives might be constructed. Empathizing with people who are very different from us involves getting to "know their stories" (Gallagher 2012, 370), and collaborative construction of a narrative facilitates a progressively more refined appreciation of how an experience is situated in a life. ${ }^{12}$

One might object that empathy involves experiencing something of the other person's experience, rather than understanding it in a non-phenomenological way. And, to the extent that we rely on narrative, it seems we are relying on something that does not incorporate the 
necessary engagement with experience. However, consider the following analogy: Suppose you are intensely scrutinizing a painting in a gallery, absorbed in your experience of it. At the same time, you listen to a tour guide's detailed and erudite talk about the painting. As you hear details of its history, the artistic techniques used, and the concerns of the artist at the time, your experience of the painting is altered and enriched. You attend to features that you were previously oblivious to, reinterpret others, and appreciate various ambiguities. Hence experience of the painting, when conceived of dynamically, is not independent of its contextualization. Similarly, the progressive narrative-construction that features in an empathic process cannot be neatly separated from an appreciation of experience. This is consistent with the view that the empathizer's experience differs from that of the target. The two parties will not share the same narratives. It can be added that the narratives they both adopt are changeable, negotiable and often assembled cooperatively.

As the analogy of the painting further indicates, an empathic process that yields a positive appreciation of experience is not simply to be identified with a specific form of imagination. It could, in principle, make use of the empathizer's full range of cognitive abilities, including areas of theoretical and practical expertise, the application of general knowledge, and various different interpersonal skills. Granted, one might draw upon one's own past experiences in appropriate ways, as well as imagine how one might feel in certain situations. But empathy also draws on a much wider range of imaginative abilities, to make connections between various aspects of experience and to situate them in the context of a person's life. In a loose sense, empathy of this kind might be said to involve "reconstructing" someone's experience, but this is not to be identified with a singular cognitive achievement, such as a sub-type of imagination, and it does not involve taking on someone else's firstperson perspective in place of one's own. 


\section{Second-person experience}

Without occupying the other person's perspective or projecting one's own first-person perspective upon it, in what sense can one be said to experience something of what she experiences? In order to answer that question, a distinctive kind of second-person experience needs to be acknowledged. To clarify its nature, I will draw upon an approach to empathy that originates in the phenomenological tradition. Take Edith Stein's account, for instance. She maintains that we have two distinct modes of access to experience, first-person and second-person, where the latter is qualitatively different from the former rather than an imaginative extension of it. She treats empathy as a "kind of act of perceiving," a type of intentional state that is distinctive in virtue of its having someone else's experience as its content ([1917] 1989, 11-12). More recently, this view has been adopted, further developed and defended by philosophers such as Zahavi $(2001,153)$, who treats empathy as a "specific mode of consciousness," and Thompson $(2007,388)$, who likewise regards it as a "sui generis kind of intentional experience."

There are several problems with this general approach. First of all, there is the risk of vagueness. Take Stein's claim that we "perceive" the mental lives of others (see also Zahavi 2010 , 2011). It is unclear what is meant by this, given a lack of engagement with debates concerning the nature and limits of sensory perceptual content. ${ }^{13}$ Talk of "perception" is also in tension with the view that empathy is a sui generis type of intentionality. If empathy is a matter of perception, then it is not a type of intentional state in its own right. However, if it is "different from perception, recollection and fantasy" (Zahavi 2007, 36), there is - in the absence of further qualification—even less clarity over the kind of "immediacy" with which others' mental lives are experienced. Either way, the most that can be said with confidence is that one understands - to at least some degree - certain experiences had by other people, 
without recourse to conscious inference from one's own experience. And, regardless of whether we call this "perceptual” (in some sense of the term), "quasi-perceptual," or "perception-like," it is perhaps too accommodating. Without recourse to inference, we can surely appreciate the meaning of someone's expression as we indifferently brush by her on the street, and we can similarly "see" the purposiveness of a group of people walking in the same direction. There is also the concern that empathy, construed in this way, can supply only a superficial understanding of experience. We might "see" that someone is happy, distressed, upset, and so on, but we are less often able to "see" the contents of such emotions - what it is that someone is happy, distressed or upset about. Without the provision of additional information, use of conscious inference or both, we are even less likely to "see" why she is having an experience with that content.

However, setting aside the talk of "perception," what I think is right about this kind of approach is the emphasis upon second-person experience: relating to a specific individual as a "you," in a way that is to be contrasted with third-person experience of a "she" or "he." This is what that I want to develop further. First of all, I suggest that the approach would benefit from a shift in focus, insofar as it emphasizes a type of intentional state rather than a longer-term process. ${ }^{14}$ This is not to suggest that there need be any tension here. Stein, for instance, does not explicitly preclude the dynamic elaboration of second-person experience. More importantly, though, the nature of second-person experience needs to be conceived of in a more specific way. It is clear that the term "second-person experience" should not be taken at face value, given that many "second-person" relations are not "personal" in the right way, or to a sufficient degree. Not all instances where a "you" is addressed are good candidates for empathy. Consider asking a cashier for an extra bag while you pack your shopping, or thanking a member of the flight crew as you disembark from a plane. What is absent in such cases is receptivity to the particularity of the person: it is of little consequence 
who you request a bag from or who you thank while leaving the plane, so long as you address someone in the right social role. The kinds of second-person relation relevant to our understanding of empathy involve engaging with who someone is, with the particularities of her experience and — in cases of sustained empathic interaction—with her life.

Darwall $(2011,4)$ describes a second-person stance in the following, more specific way: "to be genuinely with each other, persons must be jointly aware of their mutual openness to mutual relating." This is similar to what Stein, Zahavi and other advocates of the phenomenological approach mean by "second-person experience." However, unlike them, Darwall does not identify empathy with second-person relating. He construes it as a kind of imaginative performance that is just one aspect of the second-person relation. We "somehow enter into the other's perspective or feel some version of what we imagine she feels"; there is an "imaginative projection into another person's point of view" (2011, 8-10). To put it another way, it consists of explicit simulation embedded in an experience of second-person relating. However, we do not have to appeal to simulation in order to pin down a distinctively empathic form of second-person experience. I suggest that what is instead required is a distinction between two broad types of second-person relating, which I will call "personoriented" and "world-oriented."

Here is an example of world-oriented relating: suppose you walk round a museum with a friend, discussing various artefacts, sharing background knowledge, comparing appraisals, and pointing out the things that strike you. To quote J. H. van den Berg (1952, 166), on such occasions "the subject shows itself in the things." Your interactions with another person shape how you experience your surroundings, contributing to a sense of what is significant and how it is so. As well as having your own experience of the museum and appreciating that the other person has a different experience of that same museum, there is also our experience of the museum, a sense of where we are that is shaped and re-shaped by 
on-going interaction between us. How the shared environment is experienced can vary markedly, depending on who one is with and on the kinds of interpersonal interaction that ensue. Hence van den Berg's suggestion that experience of another person can be manifested principally in how one's surroundings look, rather than in a distinct and explicit sense of what she is experiencing.

The museum example involves second-person relating, but not-I suggest - empathy. This is because the two parties relate to each other in the context of exploring a shared situation; their attention is focused primarily on aspects of that situation and not on each other. However, another kind of second-person relation, which is less frequent but nevertheless still commonplace, involves focusing instead on the other person and her experience. What is explored here is one or both parties' experience, rather than their shared situation. And, as already discussed, there are two aspects to person-oriented relating: (a) a kind of attentiveness to the other person, involving openness to certain kinds of interpersonal difference; (b) an interpersonal, cooperative, exploratory process, which incorporates this attentiveness, varies considerably in its duration, sophistication, and degree of structure, and can draw on the full range of cognitive resources. This gives us all that we need in order to identify distinctively empathic second-person experiences; a certain kind of second-person relating is necessary and also sufficient for empathy. We might say that an "empathic person" is someone who is especially able to attend to others in this way; one is "being empathic" when one is attentive in this way; and one is engaged in "empathizing" when this kind of attentiveness is integrated into an interpersonal process of whatever duration, involving a balance of listening, questioning, and suggestion. When simulation features too, as it often does, it is a contingent ingredient. ${ }^{15}$

The extent to which the two aspects of empathy_- "openness" and "exploration" — are present can vary considerably, and one's ability to explore could be aided or obfuscated by

Commented [A4]: Just how much less frequent is this kind of second-person experience? My worry is that this makes it sound like empathy is a feature only of very structured clinical situations rathe than a regular feature of our engagement with one another in more "ordinary" settings and relationships.

Commented [A5R4]: I've changed the wording to make clear that it is commonplace. 
any number of factors. So empathy is not "all or nothing"; one can be empathic and achieve an empathic understanding to varying degrees. For instance, not all empathy involves face-toface encounters. There is a degree to which one can empathize with someone who is not present, with whom one may not have been in communication at all. Such cases involve the right kind of second-person orientation, which implies a readiness to engage in an interpersonal process, but without any actual engagement in that process. This applies to historical figures too; there is still a sense in which one can empathize. We can add a counterfactual here: in such cases, the empathic person, in so far as she is open to the target individual, would have engaged in an empathic process had she been able to. ${ }^{16}$ However, what is accomplished in the absence of exploration is usually lacking when compared to the fruits of prolonged, exploratory, collaborative activity. When openness to the other person is unreciprocated, one's appreciation of her experience is more likely to be indeterminate, vague, inaccurate and less particular to the target person (other than when one already knows that person well and already has much of the required narrative). ${ }^{17}$

\section{Simulation revisited}

One could continue to maintain that second-person experience depends upon implicit simulation, that "my experience of your experience" is facilitated by a non-conscious or "subpersonal" simulation mechanism (e.g., Currie 2011). However, although implicit simulation may go some way to explaining the "quasi-perceptual" nature of certain face-to-face empathic experiences, it is not at all clear how an appeal to non-conscious simulation is supposed to illuminate the nature of second-person experience, even if we concede its involvement. How is a distinctive kind of attitude towards another person to be accounted for by appealing to two first-person states (phenomenological or otherwise) that are 
isomorphic in certain respects? The appeal to implicit simulation lacks explanatory power, as it does not address the second-person structure of empathic experience.

Of course, implicit simulation is also claimed to be more widespread than the process I have described; it is allegedly a frequent or even ubiquitous contributor to interpersonal experience. Hence one could continue to endorse an additional, wider-ranging conception of empathy, as something that arises on all or almost all occasions when we observe or interact with others, the content of which is quasi-perceptual and fairly unsophisticated or "low level." I do not seek to rule out this use of the term. Nevertheless, I am not sure that it is helpful. 'Empathy', conceived of in such a permissive way, does not accommodate a contrast between empathic and non-empathic interpersonal encounters. It just amounts to

'interpersonal experience' or, more specifically, 'an essential, underlying constituent of all interpersonal experiences.' One could just as well address interpersonal experience and what it consists of without recourse to the term 'empathy', and so the term is arguably superfluous here. At the very least, it is clear that an additional conception of empathy is needed, one that does accommodate all those cases (plausibly the vast majority) where empathic experiences of people can be contrasted with unempathic and non-empathic experiences of them (where unempathic experiences involve failures of empathy, while non-empathic experiences involve an absence of empathy where it is neither required nor expected).

Although "second-person experience" is not as ubiquitous as "quasi-perceptual experience," phenomenological accounts face similar concerns - they identify something that is too wide-ranging to accommodate a contrast between empathic and unempathic/nonempathic ways of encountering a "you." As Zahavi $(2014,125)$ writes, referring first to Scheler, and then to Husserl and Stein, empathy is "what allows me to experience other subjects"; it is "the term of choice for the experience of another consciousness." Again, I do not wish to reject such uses of the term; it can simply be conceded that 'empathy' refers to at
Commented [A6]: But it would seem to be crucially informative for illuminating/understanding the contrast between the personal and the objective, i.e. the contrast between encountering something as another person and encountering something as a mere thing. (I would have thought this was something phenomenology was interested in cashing out.)
commented

Commented [A7R6]: I've changed the wording a bit. I agree that the personal/impersonal distinction is an important one. My concern is that using empathy in a permissive way, to refer to the former, doesn't add anything to our understanding and also obfuscates our doesn't add anyshing to our understanding and also obfuscates ou also goes by the name "empathy".

Commented [A8]: Apropos the above comment, this would seem to be what's at issue, rather than a deeper, clinically-oriented sense of empathy in a lot of phenomenological discussions. (I don't think observing this provides much help to simulation accounts, as far as I can see.)

Commented [A9R8]: Again, I've made some changes so that this is clearer. 
least two different things. Nevertheless, there is something to be said for limiting ourselves to the more restrictive conception of empathy. By refining and clarifying the relevant sense of “second-person experience," we retain what I think is the central insight of the phenomenological approach while also pinning down a more specific, distinctive achievement, one that tracks uses of the term 'empathy' in clinical practice and various other contexts. This achievement can also accommodate varying degrees of empathy, which depend upon the extent to which one is open to difference and able to enter into an empathic process. Hence, once the emphasis is placed upon second-person exploration rather than the perception-like character of empathy, we do not have to concede that there are qualitatively distinct, higher "levels" of empathy that rely upon explicit simulation and/or inference, as, for instance, Zahavi $(2014,151)$ does. $^{18}$

As for explicit simulation, I have argued that this can feature in empathic processes but is neither necessary nor sufficient for them. So, in order to retain a conception of empathy as explicit simulation, one would have to insist that another kind of empathy (simulation) can arise in isolation from such processes. However, the various appeals to somehow "taking up the other person's perspective" or "seeing things from her point of view" may in fact be referring to the same achievement I have described, while misconstruing its nature. Such talk does not have to be interpreted in terms of adopting someone else's first-person perspective. In order to attend to someone's experiences in an empathic way, one suspends - to varying degrees - the habitual tendency to assume commonalities and, in so doing, impose one's own experience upon her. To quote Margulies $(1989,58)$, “In looking for you, I must identify my own reflection and continually put myself aside.” Empathy involves striving to encounter someone else's experience on its own terms, and talk of transcending one's own perspective could just as easily be construed in this way. One enters - to varying degrees - someone else's perspective to the extent that one ceases to impose one's own experience upon her; one 
does not somehow become her. So simulation, in its more radical guise, may well add up to nothing more than an empathic openness to others' experience. If that is right, then simulation in the less radical sense, where one imagines oneself in someone's position and projects the resultant experience onto her, would amount to a failure of empathy, to a lack of required openness, as illustrated by the earlier example of empathizing with someone's grief.

Furthermore, explicit simulation, of whatever kind, is arguably a less reliable means of achieving much the same result that exploration facilitates. ${ }^{19}$ It is something we resort to when an empathic process is unavailable or breaks down, a point made by Stein ([1917] 1989, 14): "Should empathy fail, this procedure can make up the deficiency, but it is not itself an experience." In other words, if you are unable to engage with someone else's experience on its own terms, you resort to reflecting upon your own experience in a way that differs qualitatively from empathic attentiveness to the experience of someone else. More recently, Slaby $(2014,256)$ has similarly suggested that "the quasi-inquisitive attempt to fully 'get at' another person's perspective on the world is superfluous. Nothing is lost when one replaces this by a stance of acknowledging or recognizing the other." At best, the same outcome is achieved but in a different and less effective way.

One way to preserve an additional, simulationist form of empathy is to resort to stipulative definition: when using the word 'empathy' for certain purposes, we will take it to mean "explicit simulation," or at least "a cognitive process that essentially involves simulation." But there is the worry that the "we" in question will turn out to be "those who endorse a simulationist theory of empathy." If so, this would amount to a commitment on the part of simulation theorists to continue identifying empathy with simulation, regardless of how anyone else might use the term. The view would then be insulated from any kind of substantive debate and others could simply ignore it. Alternatively, the simulationist could take up the challenge of identifying cognitive achievements that are more generally

Commented [A10]: Cavell? His distinction between knowing and acknowledging would seem to be relevant. It seems to me that the simulationist appeals to simulation as a way really to know the other's mind (by somehow reproducing it), whereas what is at issue in the relation to the other is one of acknowledgment, where that includes an acknowledgment of the other's "separateness."

Commented [A11R10]: I'm not sufficiently familiar with Cavell's work on this, and so I'm reluctant to add anything here. I hope that's okay. 
acknowledged as instances of empathy, do centrally involve simulation, and do not involve what I have described. However, even if the simulationist were to succeed in this, it would remain the case that (a) the scope of explicit simulation may well have been overstated due to a misinterpretation of empathic openness, (b) explicit simulation is not the default or most effective way of accessing the experiences of others, and (c) implicit simulation risks being uninformative, accommodating all manner of different ways in which we experience and relate to other people. Given this, I conclude that openness-exploration is more worthy of the name 'empathy' than simulation. If empathy is to be regarded as a singular cognitive achievement, it is more plausibly a matter of this than of simulation. And, if the term 'empathy' is taken instead to encompass a number of different achievements, opennessexploration is a more plausible candidate than explicit simulation for the primary means by which we seek to understand — and indeed to experience — the experiences of others.

\section{References}

Barnes, Julian. 2013. Levels of Life. London: Jonathan Cape.

Bellet, Paul S. and Michael J. Maloney. 1991. "The importance of empathy as an interviewing skill in medicine." Journal of the American Medical Association 266: 1881-1882.

Berg, J. H. van den. 1952. "The human body and the significance of human movement: A phenomenological study." Philosophy and Phenomenological Research 13: 159-183.

Blair, Robert J. R. 2005. "Responding to the emotions of others: Dissociating forms of empathy through the study of typical and psychiatric populations." Consciousness and Cognition 14: 698-718. 
Coplan, Amy. 2011. "Will the real empathy stand up? A case for a narrow conceptualization.” The Southern Journal of Philosophy 49, Spindel Supplement: 4065.

Coplan, Amy and Peter Goldie. 2011. "Introduction.” In Empathy: Philosophical and Psychological Perspectives, edited by Amy Coplan and Peter Goldie, ix-xlvii. Oxford: Oxford University Press.

Coulehan, John L., Frederic W. Platt, Barry Egener, Richard Frankel, Chen-Tan Lin, Beth Lown, and William H. Salazar. 2001. '“Let me see if I have this right...' Words that help build empathy." Annals of Internal Medicine 135: 221-227.

Currie, Gregory. 2011. “Empathy for objects.” In Empathy: Philosophical and Psychological Perspectives, edited by Amy Coplan and Peter Goldie, 82-95. Oxford: Oxford University Press.

Darwall, Stephen. 1998. “Empathy, sympathy, care.” Philosophical Studies 89: 261-282.

—. 2006. The Second-Person Standpoint: Morality, Respect and Accountability.

Cambridge, MA: Harvard University Press.

. 2011. "Being with.” The Southern Journal of Philosophy 49, Spindel Supplement: 424.

De Vignemont, Frédérique. 2010. “Knowing other people’s mental states as if they were one's own.” In Handbook of Phenomenology and Cognitive Science, edited by Shaun Gallagher and Daniel Schmicking, 283-299. Dordrecht: Springer.

De Vignemont, Frédérique and Pierre Jacob. 2012. "What is it like to feel another's pain?" Philosophy of Science 79: 295-316.

Gallagher, Shaun. 2012. "Empathy, simulation and narrative." Science in Context 25: 355381.

Goldie, Peter. 2000. The Emotions: A Philosophical Exploration. Oxford: Clarendon Press. 
2011. “Anti-Empathy.” In Empathy: Philosophical and Psychological Perspectives, edited by Amy Coplan and Peter Goldie, 302-317. Oxford: Oxford University Press. Goldman, Alvin. 2006. Simulating Minds: The Philosophy, Psychology and Neuroscience of Mindreading. Oxford: Oxford University Press.

. 2011. "Two routes to empathy: Insights from cognitive neuroscience.” In Empathy: Philosophical and Psychological Perspectives, edited by Amy Coplan and Peter Goldie, 31-44. Oxford: Oxford University Press.

Gordon, Robert. 1995a. "Folk psychology as simulation.” In Mental Simulation, edited by Martin Davies and Tony Stone, 60-73. Oxford: Blackwell.

1995b. "Sympathy, simulation, and the impartial spectator." Ethics 105: 727-742.

Halpern, Jodi. 2001. From Detached Concern to Empathy. Oxford: Oxford University Press. .2003. "What is clinical empathy?" Journal of General Internal Medicine 18: 670674.

Havens, Leston. 1986. Making Contact: Uses of Language in Psychotherapy. Cambridge,

MA: Harvard University Press.

Hawley, Katherine and Fiona MacPherson, eds. 2011. The Admissible Contents of Experience. Oxford: Blackwell.

Hutto, Daniel D. 2004. "The limits of spectatorial folk psychology." Mind and Language 19: $548-573$.

2008. Folk Psychological Narratives: The Sociocultural Basis of Understanding Reasons. Cambridge, MA: MIT Press

Jaspers, Karl. (1913) 1963. General Psychopathology. Manchester: Manchester University Press. 
Larson, Eric B. and Xin Yao. 2005. "Clinical empathy as emotional labor in the patientphysician relationship." Journal of the American Medical Association 293: 1100 1106.

Margulies, Alfred. 1989. The Empathic Imagination. New York: W.W. Norton \& Company.

Medlicott, Diana. 1999. "Surviving in the time machine: Suicidal prisoners and the pains of prison time." Time \& Society 8: 211-230.

Mercer, Stewart W. and William J. Reynolds. 2002. "Empathy and quality of care." British Journal of General Practice (Quality Supplement): 9-12.

Pienkos, Elizabeth and Louis A. Sass. 2012. "Empathy and otherness: Humanistic and phenomenological approaches to psychotherapy of severe mental illness." Pragmatic Case Studies in Psychotherapy 8: 25-35.

Ratcliffe, Matthew. 2012. "Phenomenology as a form of empathy." Inquiry 55: 473-495. 2015. Experiences of Depression: A Study in Phenomenology. Oxford: Oxford University Press.

Ritter, Kathrin, Isabel Dziobek, Sandra Preißler, Anke Rüter, Aline Vater, Thomas Fydrich, Claas-H. Lammers, Hauke R. Heekeren, and Stefan Roepke. 2011. "Lack of empathy in patients with narcissistic personality disorder." Psychiatry Research 187: 241-247.

Rogers, Carl R. 1957. "The necessary and sufficient conditions of therapeutic personality change.” Journal of Consulting Psychology 21: 95-103.

Sherman, Nancy. 1998. "Empathy and imagination.” Midwest Studies in Philosophy XXII: $82-119$.

Slaby, Jan. 2014. “Empathy’s blind spot.” Medicine, Healthcare and Philosophy 17: 249258.

Stein, Edith. (1917) 1989. On the Problem of Empathy. Washington D.C.: ICS Publications. 
Stephan, Achim. 2015. "Empathy for artificial agents.” International Journal of Social Robotics 7: 111-116.

Stueber, Karsten R. 2006. Rediscovering Empathy: Agency, Folk Psychology and the Human Sciences. Cambridge, MA: MIT Press.

Thompson, Evan. 2007. Mind in Life: Biology, Phenomenology, and the Sciences of Mind. Cambridge, MA: Harvard University Press.

Throop, Jason C. 2010. "Latitudes of loss: On the vicissitudes of empathy." American Ethnologist 37: 771-782.

Zahavi, Dan. 2001. "Beyond empathy: Phenomenological approaches to intersubjectivity." Journal of Consciousness Studies 8 (5-7): 151-167. . 2007. "Expression and empathy." In Folk Psychology Re-assessed, edited by Daniel

D. Hutto and Matthew Ratcliffe, 25-40. Dordrecht: Springer.

2010. "Empathy, embodiment and interpersonal understanding: From Lipps to

Schutz.” Inquiry 53: 285-306.

. 2011. "Empathy and direct social perception: A phenomenological proposal."

Review of Philosophy and Psychology 2: 541-558.

2014. Self and Other: Exploring Subjectivity, Empathy, and Shame. Oxford: Oxford University Press.

\footnotetext{
${ }^{1}$ See, for example, Coplan and Goldie (2011) for discussion of how the term 'empathy' originated and the various different conceptions of what it involves.

${ }^{2}$ The German term Einfühlung, from which 'empathy' is derived, suggests that one somehow "feels into" the other person's experience, something that an emphasis on exploration captures.

${ }^{3}$ See, for example, Coplan $(2011,40)$ and Zahavi $(2014,152)$ for statements of the view that 'empathy' refers to various different cognitive achievements.

${ }^{4}$ Goldman uses the term 'mirroring,' having accepted the popular view that implicit simulation depends - in part—on a mechanism utilising the properties of "mirror neurons." See also De Vignemont (2010) for a distinction between "mirror empathy" and "reconstructive empathy."

${ }^{5}$ Other statements of the view can be found in Darwall (1998) and Coplan (2011).

${ }^{6}$ See also Sherman (1998) for a good discussion of Rogers on empathy, which identifies some of the same themes. However, Sherman goes on to couch all of this in terms of simulation, a move that I resist.

${ }^{7}$ For a similar statement, see, for example, Bellet and Maloney $(1991,1881)$.

${ }^{8}$ See also Hutto (2004) for some complementary arguments to the effect that simulation is incapable of doing

the job in situations where we do come to understand something of others' mental lives.
} 
${ }^{9}$ I do not think there are any grounds for maintaining that these points are specific to grief. More generally, projecting one's own experiences onto someone else in the absence of a certain kind of attitude towards that person does not add up to empathy, even when one modifies those experi ences accordingly and achieves a reasonable degree of accuracy.

${ }^{10}$ Empathy therefore involves adherence to certain norms of conduct. Some of these may be specific to interaction with particular individuals, and discovered or constituted through that interac tion, while others apply to second-person interaction more generally, within a particular culture or cross-culturally. See Darwall (2006) for a lengthy discussion of the normative structure of second-person relations.

${ }^{11}$ Blair (2005) distinguishes three kinds of empathy: cognitive empathy (or "theory of mind"), motor empathy, and emotional empathy. Again, the emphasis on a process structure offers a degree of unity that is otherwise lacking.

${ }^{12}$ See Hutto (2008) for a defence of the view that other aspects of interpersonal understanding also have a narrative structure.

${ }^{13}$ For several different views regarding the nature of perceptual content, see, for example, Hawley and MacPherson (2011).

${ }^{14}$ Such approaches do tend to acknowledge that "perception" of experience is a dynamic affair, involving bodily interaction between two parties. However, they do not acknowledge the longer-term process structure that I describe here.

${ }^{15}$ How does an empathic attitude differ from one of sympathy? A former colleague of mine once recounted his experience of seeing a child caught on an escalator crying out in pain. Here, there is an immediate emotional response involving some degree of identification, but without the kind of openness I have described. I would categorise this as sympathy rather than empathy. It is not so easy to distinguish the two once we reject the view that empathy involves duplication of first-person experience, but a distinction can still be drawn. In this example, one feels for the child in a way that "calls for" a certain response to the situation, a response that is not concerned with increasing one's understanding of the child's experience. Empathy, in contrast, is focused on understanding someone's experience rather than responding to it. I reject the view that one must first have an empathic experience of the child's pain in order to recognize that he is in pain and feel for him. Even so, I accept that sympathy and empathy are closely related and often occur together.

${ }^{16}$ It is also arguable that a kind of empathic process is possible in some historical cases. For example, one might adopt an empathic attitude when interacting with documents such as letters and diaries.

${ }^{17}$ It could be maintained that we empathize with literary characters as well. This is a special case for any account of empathy, and I am happy to admit that the imagination has an important and perhaps disti nctive role to play here too. However, its principal role is not that of mental simulation. Here too, one engages with experiences insofar as they are framed by narrative.

${ }^{18}$ See also Thompson (2007) for the view that there are "levels" of empathy (Thompson 2007), with simulation or something like it only occurring at certain levels.

${ }^{19}$ One could also maintain, as Stephan (2015) does, that my account is closer to what people mean by "empathy" in the context of everyday life and language than the kind of "epistemic sense of empathy" that many philosophers are concerned with. 